\title{
Radikal prostatektomi sonrası erektil fonksiyon açısından robotik cerrahi ile açık cerrahinin karșılaștırılması
}

\section{Comparison of robotic surgery and open surgery for erectile function after radical prostatectomy}

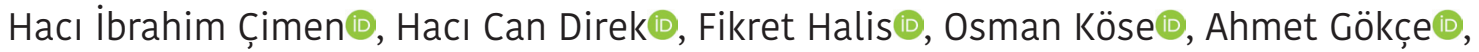
Hasan Salih Sağlam(i)

\section{öz}

AMAÇ: Prostat kanseri (PCa) nedeniyle kliniğimizde radikal prostatektomi uygulanan vakaları erektil fonksiyon açısından değerlendirmek ve uygulanan cerrahi teknikleri karşılaştırmaktır.

GEREÇ ve YÖNTEMLER: Ekim 2012 - Şubat 2018 yılları arasında kliniğimizde radikal prostatektomi operasyonu uygulanan hastaların verileri retrospektif olarak değerlendirildi. Hastalar uygulanan cerrahi tekniğe göre iki gruba ayrıldı (Grup 1: açık, Grup 2: robotik). Erektil fonksiyonu değerlendirmek için hastalardan postoperatif $1 ., 6$. ve 12. aylarda Uluslararası Erektil Fonksiyon İndeksi-5 (IIEF-EF) formunu doldurma$s 1$ istendi. IIEF-5 skoru >21 olan hastalar potent olarak kabul edildi. Gruplar postoperatif ereksiyon fonksiyonları açısından karşılaştırıldı. BULGULAR: Ortalama hasta yaşı 64,6 5,94 (50-79), ortalama prostat spesifik antijen (PSA) değeri 10,9 $\pm 9,2 \mathrm{ng} / \mathrm{dL}$ olarak bulundu. Gruplar arasında yaş, PSA, preoperatif ve postoperatif gleason skoru, patolojik evre, nörovasküler demet korunma oranı, cerrahi sınır pozitiflik oranı ve preoperatif erektil fonksiyon açısından istatistiksel olarak anlam$l_{1}$ bir fark yoktu. Postoperatif potens oranı açısından açık ve robotik cerrahi arasında postoperatif 1., 6. ve 12. aylarda anlamlı bir farklılık bulunmamıştır.

SONUC̦: Prostat kanseri nedeniyle cerrahi olarak tedavi edilen olgularda postoperatif erektil fonksiyonun korunması açısından, robotik cerrahi ile açık cerrahi benzer sonuçlara sahiptir.

Anahtar Kelimeler: radikal prostatektomi, erektil disfonksiyon, prostat kanseri

\section{ABSTRACT}

OBJECTIVE: To evaluate the patients who underwent radical prostatectomy in our clinic for the treatment of prostate cancer in terms of erectile function, and to compare them according to the applied surgical technique.

MATERIALS and METHODS: We reviewed the medical records of the patients who underwent radical prostatectomy between October 2012 and February 2018 retrospectively. The patients were divided into two groups according to the applied surgical technique (Group 1: open, Group 2: robotic). To evaluate the erectile function, patients were requested to fill out the International Index of Erectile FunctionErectile Function-5 (IIEF-5) at postoperative 1st, 6th and 12th months. Patients with IIEF-5 score $>21$ were considered as potent. Groups were compared in terms of postoperative erectile function.

RESULTS: Mean age was 64.6 \pm 5.94 (50-79) years, mean prostate specific antigen (PSA) was $10.9 \pm 9.2 \mathrm{ng} / \mathrm{dl}$. There were no statistically difference between compared groups in terms of age, PSA, preoperative and postoperative Gleason score, pathological stage, neurovascular bundle protection, positive surgical margin and preoperative erectile function. There were no statistical significant in terms of erectile function between robotic and open surgery techniques on the 1 st, 6th and 12th month postoperatively.

CONCLUSION: Robotic surgery has achieved similar outcomes to open surgery in terms of erectile function for the surgical treatment of prostate cancer.

Keywords: radical prostatectomy, erectile dysfunction, prostate cancer

\section{Gíriș}

Prostat kanseri (PCa) tanısında son yıllarda belirgin bir artış gözlenmektedir. Bu durum, organa sınırlı PCa tanısını ve buna paralel olarak radikal prostatektomi (RP) adaylarının sayısını da arttırmıştır. ${ }^{[1]}$ Hastaların görece gençleşmesi, kanser kontrolünün yanında yaşam kalitesini etkileyecek fonksiyonların da yeterli düzeyde korunması gerekliliğini ortaya çıkarmıştır. ${ }^{[2]} \mathrm{RP}$ uygulayan cerrahlar deneyim kazandıkça, tekniklerini geliştirerek daha iyi fonksiyonel sonuçların ortaya çıkmasını sağlamaktadır. ${ }^{[3]}$ RP'nin PCa'da 
kür sağladığı gösterilmiş olup, geleneksel yöntem açık RP (ARP)'dir. ${ }^{[4]}$ Cerrahi ve fonksiyonel sonuçları arttırmak adına, son iki dekatta laparoskopik RP geliştirilmiş, ancak ARP’ye göre üstünlüğü gösterilememiştir. ${ }^{[5,6]}$

Robot yardımlı RP (RYRP) esnasında cerrah operasyon sahasını ARP ile benzer şekilde 3 boyutlu görme şansına sahiptir. Buna ek olarak RYRP, yüksek seviyeli çözünürlük ve görüntülerin büyütülmesinin yanı sıra mükemmel aydınlatma olanakları sunmaktadır. ${ }^{[7]}$ ARP'de cerrah dokunma hissi ile anatomik sınırları belirleyebilir, traksiyon hissine de sahiptir. Bunlar RYRP'de olmayan özelliklerdir. ${ }^{[8]}$

Erektil disfonksiyon (ED), en az altı ay süreyle cinsel ilişkinin tümünde ya da neredeyse tümünde cinsel etkinlik sonuçlanana kadar sertleşmeyi sağlayamama ve sürdürememe veya yeterli sertleşmenin olmamasıdır. ${ }^{[0]}$ Türkiye'de 40 yaş üzerinde $\% 33$ oranında $\mathrm{ED}$ görüldüğü bildirilmiştir. ${ }^{[10]} \mathrm{ED}$ etyolojisinde birbiriyle ilişkili birçok etkeninin var olduğu bilinmektedir. Bu etyolojik nedenler; vaskülojenik, nörojenik, anatomik, hormonal, ilaç kaynaklı ve psikojenik olarak sınıflandırılabilir. ${ }^{[11]}$ Geçirilmiş pelvik cerrahi de nörojenik nedenli etyolojik faktörler arasındadır. Bu çalışmada, PCa nedeniyle ARP veya RYRP uygulanan hastaların postoperatif erektil fonksiyonlarını karşılaşırımak amaçlanmıştır.

\section{GEREÇ VE YÖNTEM}

Ekim 2012 ile Şubat 2018 tarihleri arasında Sakarya Üniversitesi Eğitim ve Araştırma Hastanesi Üroloji Kliniğinde radikal prostatektomi operasyonu uygulanan hastaların verileri retrospektif olarak değerlendirildi. Hastalar uygulanan cerrahi tekniğe göre iki gruba ayrıldı (Grup 1: açık, Grup 2: robotik). Postoperatif dönemde hastalara fosfodiesteraz Tip 5 inhibitörü (PDE5i) kullanması önerildi. Erektil fonksiyonu değerlendirmek için hastalardan postoperatif 1., 6. ve 12. aylarda Uluslararası Erektil Fonksiyon İndeksi-5 (IIEF-5) formunun doldurması istendi. ${ }^{[12]} \mathrm{Bu}$ forma göre IIEF-5 skoru $\leq 21$ olan hastaların şiddetleri değişmekle birlikte impotent olarak, IIEF-5 skoru $>21$ olan hastalar ise potent olarak kabul edildi. Gruplar postoperatif ereksiyon fonksiyonları açısından karşılaştırıldı.

\section{BULGULAR}

Toplamda radikal prostatektomi operasyonu uygulanan 177 ardışık hasta çalışmaya dahil edildi. Ortalama hasta yaşı $64,6 \pm 5,94$ yll, ortalama prostat spesifik antijen (PSA) değeri $10,9 \pm 9,2 \mathrm{ng} / \mathrm{dL}$ olarak bulundu. Hastaların 87 'si $(\% 49,2)$ cT1, 90'1 $(\% 50,8)$ ise cT2 evredeydi. Preoperatif Gleason skoru $137(\% 77,4)$ hastada 6, $29(\% 16,4)$ hastada 7, 11 hastada $(\% 6,2)$ 8-10 olarak bulunmuştur. Sadece bir hasta patolojik olarak T0 bulunmuştur. Postoperatif patolojisi
PCa olarak rapor edilen 176 hastanın 115'i $(\% 65,3)$ pT2, 61'i $(\% 34,7)$ ise pT3 evredeydi. On altı (\%9) hastada sinir korumasız cerrahi uygulanırken; $26(\% 14,7)$ hastada tek taraflı, $135(\% 76,3)$ hastada çift taraflı sinir koruma uyguland. Kırk yedi $(\% 26,5)$ hastada cerrahi sınır pozitifliği saptandı. Tüm kohort potens açısından değerlendirildiğinde, $121(\% 68,4)$ hastanın preoperatif dönemde potent olduğu tespit edildi. Postoperatif $1 ., 6$. ve 12. ayını dolduran ve potent olan hasta sayıları sırasiyla 59/177 (\%33,3), 62/161 $(\% 38,5)$ ve 77/148 (\%52) olarak bulundu. Gruplar arasında yapılan karşılaştırmada; yaş, PSA, beden kitle indeksi, Charlson komorbidite indeksi, preoperatif ve postoperatif Gleason skoru, patolojik evre, nörovasküler demet korunma oranı, cerrahi sınır pozitiflik oranı ve preoperatif erektil fonksiyon açısından istatistiksel olarak anlamlı bir farklılığın olmadığı görüldü (Tablo 1). Postoperatif dönemde potent olan hastalar postoperatif olarak değerlendirildiklerinde, potens oranı açısından RYRP ve ARP arasında postoperatif 1., 6. ve 12. aylarda anlamlı bir farklılığın olmadığı gözlendi (\%37,3; \%40,5; \%51,4 vs \%31,7; \%37,9; \%53,2 sırasılla).

\section{TARTIȘMA}

Günümüzde PCa tedavisinde hayat kalitesinin arttırılması, onkolojik sonuçların geliştirilmesiyle birlikte esas hedef haline gelmiştir. ${ }^{[13]}$ Daha iyi onkolojik ve fonksiyonel sonuçlar almak için uygulanan RYRP'nin bunu sağlayıp sağlayamadığı halen tartışılmaktadır. ${ }^{[14]}$ Çalışmamızda, RYRP ile ARP uygulanan hastalar arasinda postoperatif erektil fonksiyon açısından istatistiksel olarak anlamlı bir farklılık bulunamamıştır. Ancak, Rocco ve ark. RYRP'nin 3., 6., ve 12. ay potens oranlarının ARP'ye göre yüksek olduğunu bulmuşlar ve RYRP'nin fonksiyonel sonuçlar açısından ARP'ye göre daha etkili olduğunu belirtmişlerdir. ${ }^{[15]} \mathrm{Bu}$ çalışmada yazarlar 3., 6. ve 12. ay potens oranlarını, RYRP için sırasıyla $\% 31, \% 43$ ve $\% 61$; ARP için \%18, \%31 ve \%41 olarak raporlamışlardır. Ancak, bu çalışma incelendiğinde, ARP yapılan grupta pT3 ve pT4 hasta yoğunluğunun RYRP'ye göre istatistiksel olarak anlamlı bir biçimde yüksek olduğu; sinir koruma oranları hakkında da yeterli bir bilginin verilmediği görülecektir. Çalışmamızda gruplar arasında klinik ve patolojik evre açısından ve sinir koruma oranı açısından anlamlı bir farklılık bulunmamaktadır. Di Piero ve ark., düşük hasta yoğunluğuna sahip merkezlerde yapılan ARP ve RYRP sonuçlarını karşılaştırdıkları çalışmada, 12 aylık potens oranlarının RYRP lehine yüksek olduğunu saptamışlardır (\%55'e karşı \%26). ${ }^{[16]}$ Burada RYRP potens oranları literatürle uyumludur, ancak ARP potens oranları belirgin düşük bulunmuştur. Bu durum yazarlar tarafından, ARP sonuçlarının üç farklı cerraha, RYRP sonuçlarının ise tek cerraha ait olmasına bağlanmaktadır. Krambeck ve ark.'nın yapmıs oldukları 
Tablo 1. Hasta karakterleri

\begin{tabular}{|c|c|c|c|c|}
\hline & & Açık (n:126) & Robotik (n:51) & $P$ \\
\hline \multicolumn{2}{|l|}{ Yaş, mean \pm SD, yıl } & $64.4 \pm 5.66$ & $65.1 \pm 6.62$ & $0.46^{*}$ \\
\hline \multicolumn{2}{|l|}{ Diagnostik PSA, mean \pm SD, ng/dl } & $11.4 \pm 9.57$ & $9.7 \pm 8.48$ & $0.26^{*}$ \\
\hline \multicolumn{2}{|l|}{$\mathrm{BKi}$, mean $\pm \mathrm{SD}, \mathrm{kg} / \mathrm{m}^{2}$} & $28.5 \pm 2$ & $29.1 \pm 2.5$ & $0.09 *$ \\
\hline \multicolumn{2}{|c|}{ Charlson komorbidite indeksi $\geq 1, n,(\%)$} & $45(\% 35,7)$ & $17(\% 33,3)$ & $0.815^{* *}$ \\
\hline \multirow{2}{*}{ Preoperatif klinik evre, n, (\%) } & cT1 & $63(\% 50)$ & $24(\% 47)$ & \multirow{2}{*}{$0.86^{* * *}$} \\
\hline & cT2 & $63(\% 50)$ & $27(\% 53)$ & \\
\hline \multirow[t]{3}{*}{ Preoperatif Gleason skoru, n, \% } & 6 & $101(\% 80,1)$ & $36(\% 70,6)$ & \multirow{3}{*}{$0.13 * * *$} \\
\hline & 7 & $16(\% 12,6)$ & $13(\% 25,5)$ & \\
\hline & $8-10$ & $9(\% 7,3)$ & $2(\% 3,9)$ & \\
\hline \multirow[t]{3}{*}{ Postoperatif Gleason skoru, n, \% } & 6 & $71(\% 56,3)$ & $25(\% 50)$ & \multirow{3}{*}{$0.42 * * *$} \\
\hline & 7 & $38(\% 30,1)$ & $21(\% 42)$ & \\
\hline & $8-10$ & $17(\% 13,6)$ & $4(\% 8)$ & \\
\hline \multirow[t]{2}{*}{ Patolojik evre, n , \% } & pT2 & $82(\% 65)$ & $33(\% 66)$ & \multirow{2}{*}{$0.26^{* * *}$} \\
\hline & рт3 & $44(\% 35)$ & $17(\% 34)$ & \\
\hline \multirow[t]{2}{*}{ Cerrahi sınır durumu, n, \% } & Pozitif & $35(\% 27,8)$ & $12(\% 24)$ & \multirow{2}{*}{$0.60 * * *$} \\
\hline & Negatif & $91(\% 72,2)$ & $38(\% 76)$ & \\
\hline \multirow[t]{3}{*}{ NVD korunma durumu, n, \% } & Korunmadı & $7(\% 5,6)$ & $9(\% 17,6)$ & \multirow{3}{*}{$0.87^{* * *}$} \\
\hline & Tek taraflı & $24(\% 19)$ & $2(\% 3,9)$ & \\
\hline & Çift taraflı & $95(\% 75,4)$ & $40(\% 78,4)$ & \\
\hline \multirow{2}{*}{$\begin{array}{l}\text { Preoperatif potens durumu } \\
\text { (IIEF-5 }>21), n, \%\end{array}$} & Evet & $80(\% 63,4)$ & $31(\% 60,8)$ & \multirow{2}{*}{$0.89 * * *$} \\
\hline & Hayır & $46(\% 36,6)$ & $20(\% 39,2)$ & \\
\hline \multirow{2}{*}{$\begin{array}{l}\text { Postoperatif potens durumu } \\
\text { (IIEF-5 > 21) 1. ay, n, \% }\end{array}$} & Evet & $40(\% 31,7)$ & $19(\% 37,3)$ & \multirow{2}{*}{$0.48^{* * *}$} \\
\hline & Hayır & $86(\% 68,3)$ & $32(\% 62,7)$ & \\
\hline \multirow{2}{*}{$\begin{array}{l}\text { Postoperatif potens durumu } \\
\text { (IIEF-5>21) } 6 \text {. ay, n, } \%\end{array}$} & Evet & $47(\% 37,9)$ & $15(\% 40,5)$ & \multirow{2}{*}{$0.77^{* * *}$} \\
\hline & Hayır & $77(\% 62,1)$ & $22(\% 59,5)$ & \\
\hline \multirow{2}{*}{$\begin{array}{l}\text { Postoperatif potens durumu } \\
(\text { IIEF-5 > 21) 12. ay, n, \% }\end{array}$} & Evet & $59(\% 53,2)$ & $18(\% 51,4)$ & \multirow{2}{*}{$0.63 * * *$} \\
\hline & Hayır & $52(\% 46,8)$ & $19(\% 48,6)$ & \\
\hline
\end{tabular}

*: Bağımsız gruplarda t-testi, **: Mann-Whitney U testi, ***: Pearson ki-kare testi

BKi: Beden kitle indeksi, NVD: nörovasküler demet, IIEF-5: Uluslararası ereksiyon fonksiyon indeksi.

eşleştirmeli karşılaştırma çalışmasında ise, RYRP ve ARP arasında potens açısından postoperatif 12 . ayda herhangi bir farklılık tespit edilememiş ve potens oranları sırasıyla $\% 70$ ve $\% 62,8$ olarak rapor edilmiştir. ${ }^{[17]}$ Potens oranları, hem RYRP hem de ARP serimizden yüksektir. Bu farklılık Krambeck ve ark.'nın serilerindeki hasta popülasyonunun çalışmamızdan görece daha genç olması (61'e karşı 64,6) ve operasyon sonrası uygulanan penil rehabilitasyona hastaların uyumu ile ilgili olabilir. Çalışmamızda RP sonrası rutin olarak reçetelediğimiz PDE5i'lerin ekonomik nedenlerle hastalar tarafından düzenli kullanımının olmadığı görülmüştür.

Her ne kadar onkolojik sonuçlarımız ve potens oranlarımız bu çalışmada aynı bulunsa da; açık, laparoskopik ve robotik sonuçların karşılaştırıldığı bir çalışmada, yenilikçi ve daha az invaziv yöntemi seçen hastaların beklentilerinin geleneksel yöntemleri seçenlere göre daha yüksek olduğu; yeni teknolojinin öğrenme eğrisinde yapılan cerrahi esnasında birçok hastanın geleneksel yöntemden daha kötü sonuçlar aldığı bildirilmiştir. ${ }^{[18]}$

Çalışmamızın kısıtlılıkları olarak, her iki grubun farklı cerrahlar tarafından opere edilmesi gösterilebilir. Yine, her ne kadar RYRP'de cerrahi tecrübe arttıkça potens oranlarında herhangi bir farkın olmadığı ve potens oranının daha çok hasta ile ilgili olduğu gösterilmiş ise de ${ }^{[19]}$, robotik grubun öğrenme eğrisindeki hastalardan oluşması, gruplar arasında bir farklılığın çıkmamasına sebep olmuş olabilir. ED multifaktöryel bir hastalık ve psikolojik faktörler de bunun önemli bir parçasıdır. Bu nedenle, çalışmamızda hastaların preoperatif ve postoperatif dönemlerdeki depresyon ya da anksiyete düzeylerinin ölçülebildiği skalaların kullanılmamış olması, bir başka kısıtlılık olarak gösterilebilir. 


\section{SONUÇ}

Prostat kanseri nedeniyle cerrahi olarak tedavi edilen olgularda postoperatif erektil fonksiyonun korunması açısından, robotik cerrahi ile açık cerrahi benzer sonuçlara sahiptir. Onkolojik ve fonksiyonel sonuçların daha iyi olması için uygulanan RYRP'nin bu hedeflere ulaşabilmesi için uzun vadede daha büyük serili çalışmalara ihtiyaç vardır.

\section{Hakem Değerlendirmesi}

Dış bağımsız

Çıkar Çatışması

Yazarlar çıkar ilişkisi olmadığını beyan etmişlerdir.

Finansal Destek

Herhangi bir mali destek alınmamıştır.

\section{Peer-review}

Externally peer-reviewed.

Conflict of Interest

No conflict of interest was declared by the authors.

\section{Financial Disclosure}

No financial disclosure was received.

\section{KAYNAKLAR}

1. Schröder FH, Carter HB, Wolters T, van den Bergh RC, Gosselaar C, Bangma CH, Roobol MJ. Early detection of prostate cancer in 2007. Part 1: PSA and PSA kinetics. Eur Urol 2008;53:468-77. [CrossRef]

2. Kim SC, Song C, Kim W, Kang T, Park J, Jeong IG, et al. Factors determining functional outcomes after radical prostatectomy: robot-assisted versus retropubic. Eur Urol 2011 Sep; 60:413-9. [CrossRef]

3. Trinh QD, Bjartell A, Freeland SJ, Hollenbeck BK, Hu JC, Shariat SF, et al. A systematic review of the volume-outcome relationship for radical prostatectomy. Eur Urol 2013;64:786-98. [CrossRef]

4. Bill-Axelson A, Holmberg L, Garmo H, Rider JR, Taari K, Busch C, et al. Radical prostatectomy or watchful waiting in early prostate cancer. N Engl J Med 2014;370:932-42. [CrossRef]

5. Ficarra V, Novara G, Rosen RC, Artibani W, Carroll PR, Costello A, et al. Systematic review and meta-analysis of studies reporting urinary continence recovery after robot-assisted radical prostatectomy. Eur Urol 2012;62:405-17. [CrossRef]

6. Moran PS, O’Neil M, Teljeur C, Flattery M, Murphy LA, Smyth G, Ryan M. Robot-assisted radical prostatectomy compared with open and laparoscopic approaches: a systematic review and metaanalysis. Int J Urol 2013;20:312-21. [CrossRef]
7. Nilsson AE, Carlsson S, Laven BA, Wiklund NP. Karolinska prostatectomy: a robot-assisted laparoscopic radical prostatectomy technique. Scand J Urol Nephrol 2006;40:453-8. [CrossRef]

8. Hanglind E, Carlsson S, Stranne J, Wallerstedt A, Wilderang $\mathrm{U}$, Thorsteinsdottir $\mathrm{T}$, et al. Urinary Incontinence and Erectile Dysfunction After Robotic Versus Open Radical Prostatectomy: A Prospective, Controlled, Nonrandomised Trial. Eur Urol 2015;68:216-25. [CrossRef]

9. American Psychiatric Association. Diagnostic and statistical manual of mental disorders, 5th ed. VA: Arlington; 2013. [CrossRef]

10. Çayan S, Kendirci M, Yaman Ö, Aşçı R, Orhan I, Usta MF, et al. Prevalence of erectile dysfunction in men over 40 years of age in Turkey: Results from the Turkish Society of Andrology Male Sexual Health Study Group. Turk J Urol 2017;43:122-129. [CrossRef]

11. Gratzke C, Angulo J, Chitaley K, Dai YT, Kim NN, Paick JS, et al. Anatomy, physiology, and pathophysiology of erectile dysfunction. J Sex Med 2010;7(1 Pt 2):445-75. [CrossRef]

12. Rosen RC, Cappelleri JC, Smith MD, Lipsky J, Peña BM. Development and evaluation of an abridged, 5-item version of the International Index of Erectile Function (IIEF-5) as a diagnostic tool for erectile dysfunction. Int J Impot Res 1999;11:319-26.

13. Çimen Hİ, Sağlam HS. Robotik prostat cerrahisi ve cinsel fonksiyon. Androl Bull 2016;18:79-82.

14. Masterson TA, Cheng L, Boris RS, Koch MO. Open vs. roboticassisted radical prostatectomy: a single surgeon and pathologist comparison of pathologic and oncologic outcomes. Urol Oncol 2013;31:1043-8. [CrossRef]

15. Rocco B, Matei DV, Melegari S, Ospina JC, Mazzoleni F, Errico $\mathrm{G}$, et al. Robotic vs open prostatectomy in a laparoscopically naive center: a matched-pair analyses. BJU Int 2009;104:991-5. [CrossRef]

16. Di Pierro GB, Baumeister P, Stucki P, Beatrice J, Danuser H, Mattei A. A prospective trial comparing consecutive series of open retropubic and robot-assisted laparoscopic radical prostatectomy in a centre with a limited caseload. Eur Urol 2011;59:1-6. [CrossRef]

17. Krambeck AE, DiMarco DS, Rangel LJ, Bergstralh EJ, Myers RP, Blute ML, Gettman MT. Radical prostatectomy for prostatic adenocarcinoma: a matched comparison of open retropubic and robot-assisted techniques. BJU Int 2009;103:448-53. [CrossRef]

18. Finkelstein J, Eckersberger E, Sadri H, Taneja SS, Lepor H, Djavan B. Open Versus Laparoscopic Versus Robot-Assisted Laparoscopic Prostatectomy: The European and US Experience. Rev Urol 2010;12:35-43.

19. Zorn KC, Wille MA, Thong AE, Katz MH, Shikanov SA, Razmaria A, et al. Continued improvement of perioperative, pathological and continence outcomes during 700 robot-assisted radical prostatectomies. Can J Urol 2009;16:4742-9. 